\title{
Correction to: Diffuse leptomeningeal glioneuronal tumor in a Chinese adult: a novel case report and review of literature
}

\author{
Honghao Xu ${ }^{1} \cdot$ Fangqing Chen ${ }^{1} \cdot$ Haitao $\mathrm{Zhu}^{1} \cdot$ Lei Luo $^{1} \cdot$ Rui Zhang $^{1}$
}

Published online: 22 January 2020

(c) Belgian Neurological Society 2020

\section{Correction to: Acta Neurologica Belgica}

https://doi.org/10.1007/s13760-019-01262-9

The article "Diffuse leptomeningeal glioneuronal tumor in a Chinese adult: a novel case report and review of literature", written by "Honghao Xu, Fangqing Chen, Haitao Zhu, Lei Luo, and Rui Zhang", was originally published electronically on the publisher's internet portal (currently SpringerLink) on 24th December 2019 with open access. With the author(s)' decision to step back from Open Choice, the copyright of the article changed on 20th January 2020 to (c) Belgian Neurological Society 2020 and the article is forthwith distributed under the terms of copyright.

The original article has been updated.

The original article can be found online at https://doi.org/10.1007/ s13760-019-01262-9.

Rui Zhang

neurosurgeonzr@njmu.edu.cn

1 Department of Functional Neurosurgery, The Brain Hospital Affiliated to Nanjing Medical University, Nanjing 210029, China

Publisher's Note Springer Nature remains neutral with regard to jurisdictional claims in published maps and institutional affiliations. 